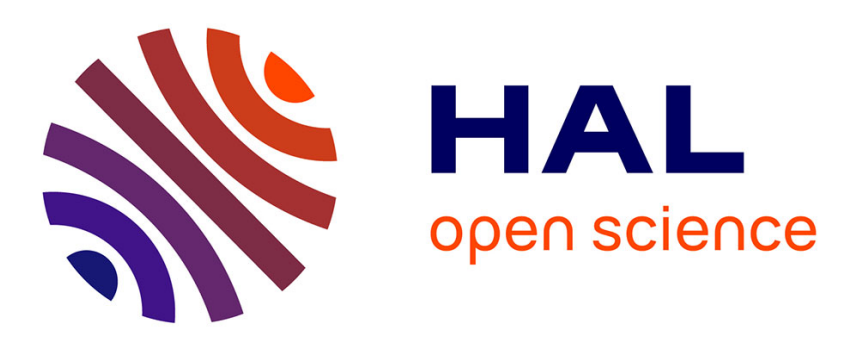

\title{
Determination of composition, residual stress and stacking fault depth profiles in expanded austenite with energy-dispersive diffraction
}

Sébastien Jegou, T.L. Christiansen, M. Klaus, Ch. Genzel, M.A.J. Somers

\section{- To cite this version:}

Sébastien Jegou, T.L. Christiansen, M. Klaus, Ch. Genzel, M.A.J. Somers. Determination of composition, residual stress and stacking fault depth profiles in expanded austenite with energy-dispersive diffraction. Thin Solid Films, 2013, 530, pp.71-76. 10.1016/j.tsf.2012.06.029 . hal-01084710

\author{
HAL Id: hal-01084710 \\ https://hal.science/hal-01084710
}

Submitted on 20 Nov 2014

HAL is a multi-disciplinary open access archive for the deposit and dissemination of scientific research documents, whether they are published or not. The documents may come from teaching and research institutions in France or abroad, or from public or private research centers.
L'archive ouverte pluridisciplinaire $\mathbf{H A L}$, est destinée au dépôt et à la diffusion de documents scientifiques de niveau recherche, publiés ou non, émanant des établissements d'enseignement et de recherche français ou étrangers, des laboratoires publics ou privés. 


\title{
Determination of composition, residual stress and stacking fault depth profiles in expanded austenite with energy-dispersive diffraction
}

\author{
S. Jegou ${ }^{\text {a, } *, 1}$, T.L. Christiansen ${ }^{\text {a }}$, M. Klaus ${ }^{\text {b }}$, Ch. Genzel ${ }^{\text {b }}$, M.A.J. Somers ${ }^{\text {a }}$ \\ a Technical University of Denmark, Dept. Mechanical Engineerings, Kgs. Lyngby, Denmark \\ ${ }^{\mathrm{b}}$ Helmholtz-Zentrum Berlin für Materialien und Energie GmbH, Berlin, Germany
}

Keywords:

Surface engineering

Residual stress

Energy-dispersive diffraction

Reconstruction profile

\begin{abstract}
A B S T R A C T
A methodology is proposed combining the scattering vector method with energy dispersive diffraction for the non-destructive determination of stress- and composition-depth profiles. The advantage of the present method is a relatively short measurement time and avoidance of tedious sublayer removal; the disadvantage as compared to destructive methods is that depth profiles can only be obtained for depth shallower than half the layer thickness. The proposed method is applied to an expanded austenite layer on stainless steel and allows the separation of stress, composition and stacking fault density gradients.
\end{abstract}

\section{Introduction}

Residual stresses are widely and deliberately introduced within the near surface region of materials to locally modify the mechanical properties and enhance the component performance with respect to wear and/or fatigue. Surface engineering associated with tailoring of the surface properties and residual stress can be achieved by thermal, chemical or mechanical treatment [1] and yields a functionally graded material that changes its properties from surface to interior. The quantification of residual stress-depth profiles to investigate the effect of the surface engineering treatment can be performed by X-ray diffraction analysis [2]. This technique relies on the determination of $h k l$ specific lattice strains for various orientations of the scattering vector with respect to the sample surface normal combined with an appropriate grain-interaction model [3]. Numerous factors affect the so-called X-ray diffraction stress analysis, e.g. grain size, triaxiality of the stress state and preferred orientation. The evaluation of stress-depth profiles in functionally graded materials can be influenced by the stress gradient itself, as well as by other gradients. Steep residual stress gradients can lead to the so-called ghost stresses, i.e. systematic errors inherent to the applied measurement and/or evaluation procedure, if no precautions are taken.

When superimposition of composition and stress gradients occurs, such as for a composition-induced stress gradient, stress evaluation

* Corresponding author at: Arts \& Métiers ParisTech, MécaSurf Laboratory, 2 cours des Arts et Métiers, 13617 Aix-en-Provence, France. Tel.: + 33 442938174; fax: + 33 442938114.

E-mail addresses: sebastien.jegou@ensam.eu (S. Jegou), tch@mek.dtu.dk (T.L. Christiansen), klaus@helmholtz-berlin.de (M. Klaus), genzel@helmholtz-berlin.de (C. Genzel), somers@mek.dtu.dk (M.A.J. Somers).

${ }^{1}$ Now with: Arts \& Métiers ParisTech, MécaSurf Laboratory, Aix-en-Provence, France. over the information depth also depends on composition, because the reference spacing is composition dependent. This can lead to dramatic ghost stresses if not taken into account during data acquisition and evaluation $[4,5]$.

Among the various techniques developed for non-destructive depth resolved stress determination [3,6-9], energy-dispersive diffraction methods, using white radiation, give some advantages associated with multiple reflections recorded in one energy spectrum and deeper information depths [10-13]. Stress-induced errors can effectively be avoided combining a modified multi-wavelength approach with the $\sin ^{2} \psi$ method or the scattering vector method [14]. In [15] it was shown that the energy-dispersive method can be applied even to the detection of very steep in-plane residual stress gradients in surface treated hard coatings, if the information depth is adapted to the steepness of the gradient. However, for a compositioninduced (self-induced) stress gradient, the 'optimisation procedure' developed for the scattering vector method cannot be applied straightforwardly, because the lattice spacing in the strain-free direction varies with the information depth. Instead a $\sin ^{2} \psi$-based approach should be considered, where $\sin ^{2} \psi$ dependencies at prechosen information depths are evaluated by interpolation among the experimental data. The reference lattice parameter for the appropriate information depth follows from interpolation among the data in the strain free direction or from independent spectroscopic analysis and knowledge of the relation between lattice parameter and composition.

This work deals with the evaluation of residual stress by means of non-destructive energy-dispersive diffraction under the influence of steep stress- and composition gradients. Steep superimposed multigradients arise after low temperature thermochemical surface treatments of stainless steel [16]. Such treatments (nitriding, carburising or nitrocarburising) give rise to the formation of a surface zone of 
so-called expanded austenite which essentially is a solid solution of colossal amounts of interstitials (carbon and/or nitrogen) in the austenite lattice. This results in biaxial compressive residual stresses of several GPa's that find their origin in the lattice misfit between the expanded austenite "case" and the untreated core [16,17].

\section{Non destructive depth profiling with energy-dispersive X-ray stress analysis}

$\mathrm{X}$-ray stress analysis is based on the lattice strain measurement $\varepsilon$ ${ }_{\varphi \psi}{ }^{h k l}$ experienced by a set of lattice planes $\{h k l\}$ in a given direction defined by the azimuth, $\varphi$, and inclination, $\psi$, with respect to the sample surface normal (Fig. 1):

$\varepsilon_{\varphi \psi}^{h k l}=\frac{d_{\varphi \psi}^{h k l}}{d_{o}^{h k l}}-1$

where $d_{o}^{h k l}$ is the unstrained lattice spacing.

In energy-dispersive diffraction using a white beam, measurements are carried out for fixed and predetermined diffraction and scattering angles. The Bragg equation then takes the following form:

$d^{h k l}=\frac{h c}{2 \sin \theta} \frac{1}{E^{h k l}}$

where $2 \theta$ is the scattering angle, $h$ is Planck's constant, $c$ is the velocity of light and $E^{h k l}$ is the energy for which diffraction of the $h k l$ lattice planes occurs.

Introducing Eq. (2) in Eq. (1) gives the lattice strain $\varepsilon_{\varphi \psi}^{h k l}$ in the measuring direction defined by $\varphi$ and $\psi$ as:

$\varepsilon_{\varphi \psi}^{h k l}=\frac{E_{o}^{h k l}}{E_{\varphi \psi}^{h k l}}-1$

where $E_{o}^{h k l}$ corresponds to the unstrained lattice spacing $d_{o}^{h k l}$.For surface engineered quasi-isotropic polycrystalline materials usually a state of rotationally symmetric biaxial stress $\left(\sigma_{13}=\sigma_{23}=\sigma_{33}=0\right.$ and $\sigma_{11}=\sigma_{22}=\sigma_{/ /}$) can be assumed, leading to:

$\varepsilon_{\psi}^{h k l}(z)=2 S_{1}^{h k l} \sigma_{/ /}(z)+\frac{1}{2} S_{2}^{h k l} \sigma_{/ /}(z) \sin ^{2} \psi$

where $S_{1}^{h k l}$ and $1 / 2 S_{2}^{h k l}$ are diffraction elastic constants, depending on the crystal orientation $h k l$ and elastic interaction among the crystals. The lattice spacing, $\left\langle d_{\psi}^{h k l}\right\rangle$ (or equivalently the energy at which diffraction occurs) determined in an X-ray diffraction experiment for a

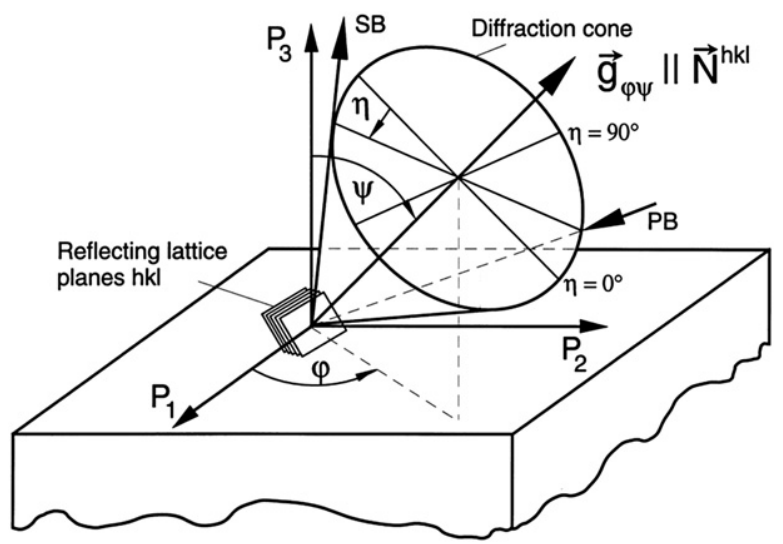

Fig. 1. Diffraction geometries in X-ray stress analysis from [17]. $\eta$ denotes the rotation of the sample around the scattering vector $\vec{g}_{\infty \psi}$ for a fixed measuring direction $(\varphi, \psi)$ with respect to the sample system $P$. PB and SB denote primary and secondary (diffracted) beam. sample (or layer) of thickness, $t$, is the diffracted intensity-weighted average over depth, $z$, i.e.:

$\left\langle d_{\psi}^{h k l}\right\rangle=\frac{\int_{0}^{t} d_{\psi}^{h k l}(z) \exp \{-\mu(E) k z\} d z}{\int_{0}^{t} \exp \{-\mu(E) k z\} d z}$

where, for measurement in reflection geometry (as practised in the present work)

$k=\frac{2 \sin \theta \cos \psi}{\sin ^{2} \theta-\sin ^{2} \psi+\cos ^{2} \theta \sin ^{2} \psi \sin ^{2} \eta}$

describes the diffraction geometry, $\mu(E)$ is the linear absorption coefficient which, for a homogeneous layer, depends on the photon energy and $\eta$ denotes the rotation angle around the scattering vector, $\vec{g}_{p \psi}$ (Fig. 1). For completeness it is mentioned that $\mu(E)$ depends on composition. This second order effect is not considered here. ${ }^{2}$ Hence, it is obtained for the lattice strain, averaged over the diffracting volume, $\left\langle\varepsilon_{\psi}^{h k l}\right\rangle$ :

$\left\langle\varepsilon_{\psi}^{h k l}\right\rangle=\frac{\int_{0}^{t} d_{\psi}^{h k l}(z) \exp \{-\mu(E) k z\} d z}{\int_{0}^{t} d_{0}^{h k l}(z) \exp \{-\mu(E) k z\} d z}-1$

Note that these equations are only valid for the case where the studied layers are well within the gauge volume. From Eq.(6) it is observed that the lattice strain evaluated for experimental lattice spacings has to be evaluated from strained and unconstrained lattice spacings weighted over the same depth range. This lattice strain can be assigned to the information depth, $\tau$ :

$\tau(E)=\langle z\rangle=\frac{\int_{0}^{t} z \cdot \exp \{-\mu(E) k z\} d z}{\int_{0}^{t} \exp \{-\mu(E) k z\} d z}=\frac{1}{\mu(E) k}+t \frac{\exp \{-\mu(E) k t\}}{\exp \{-\mu(E) k t\}-1}$

Note that the information depth in a layer is maximally $t / 2$ for the case where the layer can be considered infinitely thin as compared to the penetration of the X-rays. ${ }^{3}$ For an infinitely thick layer the information depth equals $1 /[\mu(E) k]$, which for the present case amounts to $27 \mu \mathrm{m}$. It is important to realise that, in general, $\left\langle d_{\psi}^{h k l}\right\rangle$ and $\left\langle d_{o}^{h k l}\right\rangle$ are not experimentally determined at the same information depth, because the strain-free lattice spacing applies only for one specific value for $\psi$ (and thus $\tau$ ), the so-called strain-free direction, $\psi_{0}$, defined by $\sin ^{2} \psi_{0}=-\frac{2 S_{1}^{h k l}}{\frac{1}{2} S_{2}^{k l l}}$ (as obtained by equating Eq. (4) to zero). Consequently, application of Eq. (6) requires that a value for $\left\langle d_{o}^{h k l}\right\rangle$ at $\tau_{\psi}$ is obtained by interpolation among the experimentally determined strain-free lattice spacing-depth profile $\left\langle d_{o}^{h k l}(z)\right\rangle$.

In the case of stress-depth profiling, various methods have been developed, based on either successive layer removal (destructive methods) or assigning the evaluated data to a depth below the surface (non-destructive methods). According to Eqs. (7) and (5b) for a fixed value of $\theta$ the information depth can be varied by variation of the angles $\psi$ and $\eta$ or, for energy dispersive analysis, by selecting another energy $E$ where diffraction occurs. In the present work the scattering vector method (varying $\eta$ and $\psi$ ) and the multi-wavelength method (varying $E$ and $\psi$ ) are combined for non-destructive depth profiling of the composition, stress and stacking fault probability in low temperature hardened stainless steel.

\footnotetext{
${ }^{2}$ For the present case where a layer of expanded austenite on stainless steel is considered, the error in assuming $\mu(E)$ independent of depth (i.e. a homogeneous layer) lies in the range 3.94 to $4.39 \%$ for a composition ranging from $\mathrm{y}_{\mathrm{N}}=0.30$ to $\mathrm{y}_{\mathrm{N}}=0.50$ (cf. Fig. 4).

${ }^{3}$ For 'Real space' method, the measuring depths are not limited to $t / 2$ since the gauge volume is used to define the observed volume.
} 


\section{Experimental details}

\subsection{Nitriding}

A disc of AISI $316 \mathrm{~L}$ stainless steel with diameter $10 \mathrm{~mm}$ was ground and polished to a mirror like finish. The final thickness of the disc was $2.18 \mathrm{~mm}$. The disc was austenitised in flowing hydrogen at a temperature of $1355 \mathrm{~K}$ in order to obtain a fully recrystallized austenitic structure in the sample. Nitriding was performed in a Netzsch 449 thermo-balance equipped with electronic mass-flow controllers for accurate gas control. The sample was activated in a gaseous atmosphere and subsequently nitrided at $440{ }^{\circ} \mathrm{C}$ for $14 \mathrm{~h}$ in a gas mixture consisting of $100 \mathrm{ml} / \mathrm{min} \mathrm{NH}_{3}+5 \mathrm{ml} / \mathrm{min} \mathrm{N}_{2}\left(\mathrm{~N}_{2}\right.$ was led through the measurement compartment to protect the electronics of the apparatus from interaction with $\mathrm{NH}_{3}$ ). This treatment yielded a zone of expanded austenite with a thickness of about $16 \mu \mathrm{m}$.

\subsection{X-ray diffraction}

The energy dispersive diffraction experiments were performed at the materials science beamline EDDI@BESSY II [18]. The white synchrotron beam with usable photon energies between about $8 \mathrm{keV}$ and $120 \mathrm{keV}$ is provided by a superconducting $7 \mathrm{~T}$ multipole wiggler. The primary beam cross-section was $0.3 \times 0.3 \mathrm{~mm}^{2}$, the equatorial divergence $\Delta 2 \theta$ in the diffracted beam was limited by a double slit system with an aperture of $0.03 \times 5 \mathrm{~mm}^{2}$ to values smaller than $0.01^{\circ}$. Hence, the gauge volume (which is the part of the sampling volume defined by the beam limiting slits, that immerses in the sample) takes a rather complex geometrical shape [19]. In the case of steel, however, the limiting factor for the information depth is not given by this 'geometrical' gauge volume but due to the high absorption by the $1 /$ e information depth $\tau(E)=1 /[\mu(E) \cdot k]$ (cf. Eq. (7)). Reference measurements were carried out under identical experimental conditions on stress-free powder to ensure that geometrically induced line shifts were smaller than $\Delta \mathrm{E}=10 \mathrm{eV}$ and therefore, had not to be taken into account in data evaluation. A measuring time of $300 \mathrm{~s}$ was chosen for recording the diffraction patterns in order to achieve good counting statistics. For data acquisition a solid state germanium detector (Canberra model GL0110) was used.

The 111 and 200 diffraction lines of the expanded austenite phase were investigated. The $\left\langle d_{\psi}^{h k l}\right\rangle$ versus the information depth $\tau$ were evaluated for a constant diffraction angle $2 \theta=8^{\circ}$ and azimuth $\varphi=0^{\circ}$ at nine different $\psi$ angles, ranging from $18.43^{\circ}$ to $71.57^{\circ}$. For each value of $\psi, 18$ values of the rotation angle $\eta$ about the scattering vector were selected. The range of rotation angles, $\eta$, depends on the inclination angle, $\psi$; the larger $\psi$ the smaller is the range of $\eta$ values. According to Fig. 1 the orientation $\eta=90^{\circ}$ corresponds to the $\Psi$-mode of X-ray stress analysis and, therefore, to the largest information depth. The case $\eta=0^{\circ}$ corresponds to the $\Omega$-mode $(\psi<0)$ and can only be realised for $\theta>\psi$. For the small Bragg angles between about $4^{\circ}$ and $10^{\circ}$ used in ED diffraction, this condition is usually not fulfilled. Here, the minimum rotation angle $\eta$ which would correspond to an inclination angle $\alpha$ between the incoming beam and the sample surface, is given by $\eta_{\min }=\arcsin \left[\sqrt{\sin ^{2} \psi-\sin ^{2} \theta} /(\sin \psi \cos \theta)\right]$ [20]. The diffraction elastic constants for the analysed reflections were calculated using the Eshelby/Kröner model with the single crystal constants of Fe-18Cr-12Ni [21].

\section{Results and interpretation}

An energy spectrum of the nitrided sample is given in Fig. 2. Both expanded austenite and the unaffected austenite in the substrate are observed; the 111 line profiles are observed at 40 and $42.8 \mathrm{keV}$ for expanded austenite and austenite, respectively. The difference in energy position between the peaks for expanded austenite (case) and

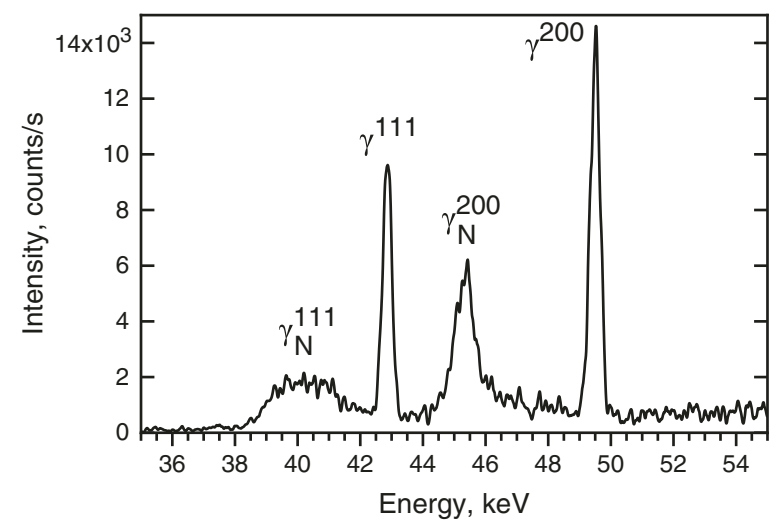

Fig. 2. (Smoothed) energy spectrum of nitrided $316 \mathrm{~L}$ stainless steel. $2 \theta=8^{\circ}, \varphi=0^{\circ}$, $\psi=18.43^{\circ}, \eta=86.9^{\circ}$, counting time: 300 s. Expanded austenite and austenite are denoted by $\gamma_{N}$ and $\gamma$ respectively.

austenite (core) is attributed to the combined effect of residual stress, composition and stacking fault energy (see [22]). Asymmetry of the peaks obtained for expanded austenite is ascribed to the presence of gradients in stress, composition and stacking fault probability, where those in stress and composition will dominate [22]. In addition, also texture gradients could contribute to the asymmetry. Such texture gradients originate from grain rotation caused by plastic deformation in the expanded austenite case during growth [23]. Recognising that the line profiles are an average over a depth range and, thus, a certain part of the profile, the centroid position of the $\gamma_{N}$ line profile was taken as the peak position and assigned to the information depth (cf. Eq. (7)). ${ }^{4}$

The lattice spacing $\left\langle d_{\psi}^{h k l}\right\rangle$ as measured for nine different $\psi$ angles and $18 \eta$ angles per value of $\psi$ is given in Fig. 3a as a function of the corresponding information depth $\tau$. Clearly, the variation in $\tau$ realised by rotation about the diffraction vector is largest for the lowest value of $\psi$ and is ascribed to larger range of $\eta$ values for smaller $\psi$. The data in Fig. 3a is assigned to relatively shallow information depths, smaller than $\mathrm{t} / 2=8 \mu \mathrm{m}$ (see comment below Eq. (7)). From interpolation among the data in Fig. 3a it is possible to evaluate a $\left\langle d_{\psi}^{111}\right\rangle$ vs $\sin ^{2} \psi$ dependence at a chosen value for $\tau$. An example is given in Fig. 3b at a depth of $4 \mu \mathrm{m}$ (indicated by the vertical dashed line in Fig. 3a). Within experimental accuracy a straight line is obtained, suggesting no influence of steep stress/composition gradients on the evaluation method.

The dependence of the strain-free lattice spacing on information depth was obtained by linear interpolation in $\left\langle d_{\psi}^{111}\right\rangle$ vs $\sin { }^{2} \psi$ and $\left\langle d_{\psi}^{200}\right\rangle$ vs $\sin ^{2} \psi$ data for the respective strain-free directions, i.e. $\sin ^{2} \psi_{0}=0.324$ and 0.48 for 111 and 200 , respectively. The results are given in Fig. 4 and converted to the nitrogen content in expanded austenite by applying the relation determined in [24]. A non-negligible difference in lattice parameter/composition is observed for the two selected $h \mathrm{kl}$. The lattice parameter/nitrogen content determined from the 200 line profile is systematically highest. This discrepancy can be understood from the introduction of stacking faults associated with the partial plastic accommodation of the colossal, chemically induced, stresses introduced in expanded austenite during growth of this zone into the austenite substrate. The presence of stacking faults on the peak positions of 111 and 200 line profiles is antagonistic: for 200 a shift towards lower energy (higher lattice spacing) and for 111 a shift towards higher energy (lower lattice spacing) would occur, which is in agreement with the observed discrepancy. Adopting the Warren equation for the relation between the peak shift as a consequence

\footnotetext{
${ }^{4}$ It is noted that if texture gradients contribute to the asymmetry of the line profiles, an error is introduced by assigning the peak position to the centroid position.
} 

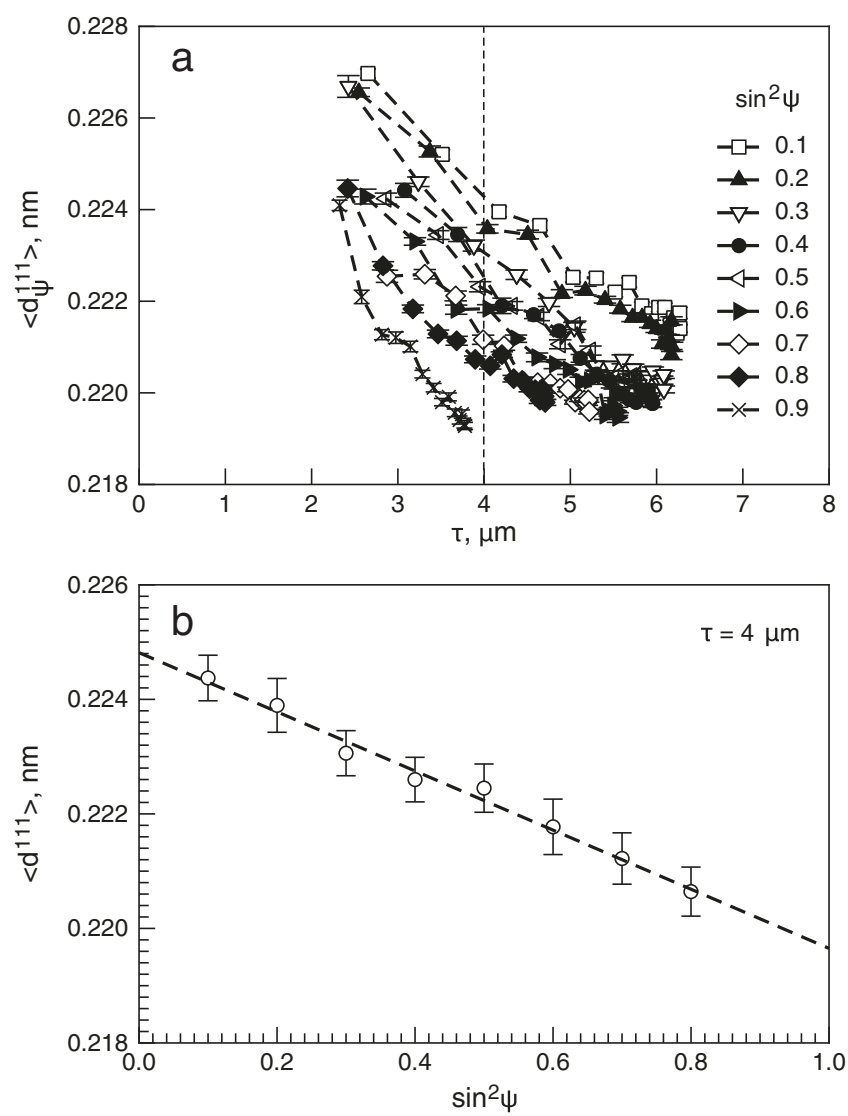

Fig. 3. a) As measured lattice spacing-depth, $\left\langle d_{\psi}^{111}\right\rangle$ vs $\tau$ profiles of expanded austenite measured with the scattering vector method applied to a nitrided $316 \mathrm{~L}$ stainless steel. b) A reconstructed $\sin ^{2} \psi$ plot at chosen information depth, $\tau$, of $4 \mu \mathrm{m}$ is also given.

of stacking faults in angle dispersed X-ray diffraction [25]:

$\Delta\left(2 \theta^{h k l}\right)=0.2756 \cdot \alpha \cdot G^{h k l} \cdot \tan \theta^{h k l}$

where $\Delta\left(2 \theta^{h k l}\right)$ is given in radians and $\alpha$ is the stacking fault probability, $G^{111}=1 / 4$ and $G^{200}=-1 / 2$. Equivalently, for the change in

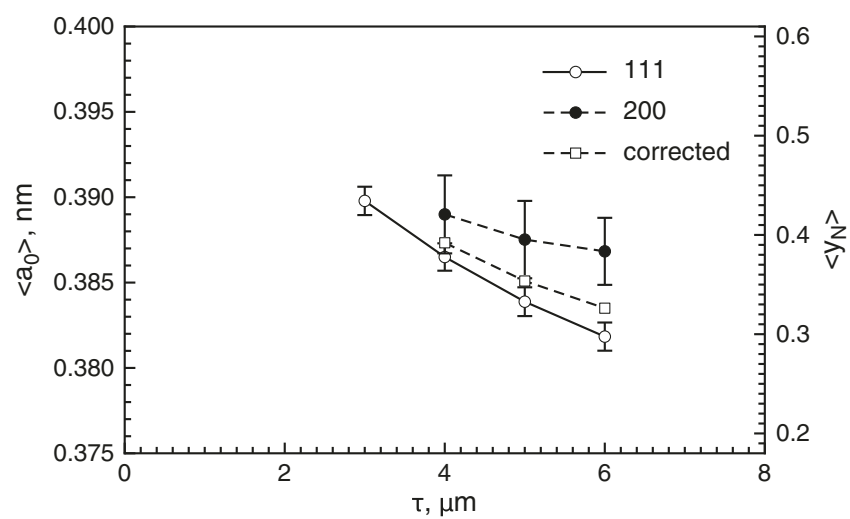

Fig. 4. Lattice parameter, $\left\langle a_{o}\right\rangle$, and associated composition-depth profiles, $\left\langle y_{N}\right\rangle$, evaluated for 111 and 200 diffraction lines of expanded austenite from the $\sin ^{2} \psi$ plots at chosen penetration depths $\tau$ and reconstructed from lattice-spacing-depth profiles $\left\langle d_{\psi}^{111}\right\rangle$ measured from the scattering vector method applied to a nitrided $316 \mathrm{~L}$ stainless steel. The corrected $\left\langle a_{0}\right\rangle$ profile was evaluated by applying Eq. (8a) and (8b), respectively. lattice spacing :

$\frac{\Delta\left(d^{h k l}\right)}{d^{h k l}}=-0.1378 \cdot \alpha \cdot G^{h k l}$

Assuming that the same composition, and thus strain-free lattice parameter should be obtained from 111 to 200 line profiles, the stacking fault probability and strain free lattice spacing can be determined, provided that the same stacking fault probabilities prevail for 111 and 200 as measured in the strain-free direction. In terms of the strain-free lattice parameter $a_{o}$, it is obtained from Eq. (8b) :

$\frac{a_{o}^{111}-a_{o}^{200}}{a_{o}}=-0.1378 \cdot \alpha \cdot\left\{\frac{1}{4}-\frac{1}{2}\right\}$

with $a^{h k l}$ the lattice parameter following from the as measured $h k l$ lattice spacing.

The depth dependencies of the strain-free lattice parameter $a_{0}$ and the stacking fault probability $\alpha$ for the depth range $\tau=4-6 \mu \mathrm{m}$ (where they can be determined), are given in Figs. 4 and 5, respectively.

Using the strain-free lattice parameter from Fig. 4, residual stresses can be evaluated for 111 and 200 reflections from interpolated graphs as Fig. 3b. Fig. 6 shows the resulting residual stress depth profiles $\sigma_{/ /}(\tau)$ for both diffraction lines 111 and 200 of expanded austenite after reconstruction of $\sin ^{2} \psi$ plots at predefined depths $\tau$. It has to be noted that the error bars are given as twice the standard deviation, which is obtained from the determination procedure of the scattering peak position and propagated through all calculations.

\section{Discussion}

Separation of stress-, composition- and stacking fault probability depth profiles from X-ray stress analysis of nitrided $316 \mathrm{~L}$ stainless steel was investigated through an energy-dispersive method. The scattering-vector method was applied for its fast depth profiling reliability and combined with a procedure for reconstruction of $\sin ^{2} \psi$ plots at chosen information depths $\tau$. It is noted explicitly that the profiles shown in Figs. 2-6 do not reflect the actual depth profiles. By straightforward calculus it can be shown that an actual depth profile, i.e. vs depth $z$, is only (in a certain depth range) identical to that for the profile vs $\tau$, if the profile depends linearly on depth [26]. In this respect it is important to realise that the lattice spacing data used for the evaluation are diffracted intensity weighted lattice spacings (cf. Fig. 3a) and that the larger information depth to which the observed lattice spacing (or stress, composition, stacking fault probability) is assigned, the less will the average value reflect the actual lattice spacing (or stress, composition, stacking fault probability) at this depth.

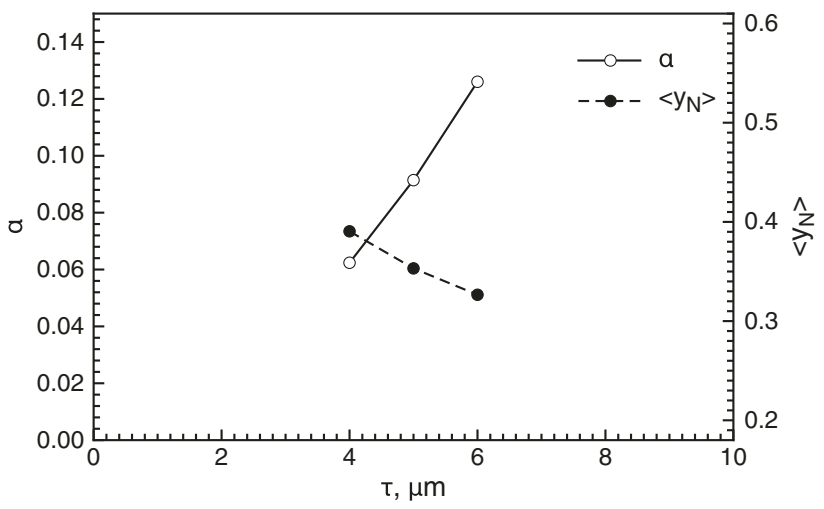

Fig. 5. Stacking fault probability, $\alpha$, vs information depth, $\tau$, determined from the antagonistic shifts of the 111 and 200 Bragg reflections. The corresponding nitrogen content, $\left\langle y_{N}\right\rangle$, is given too and identical to the drawn line in Fig. 4. 


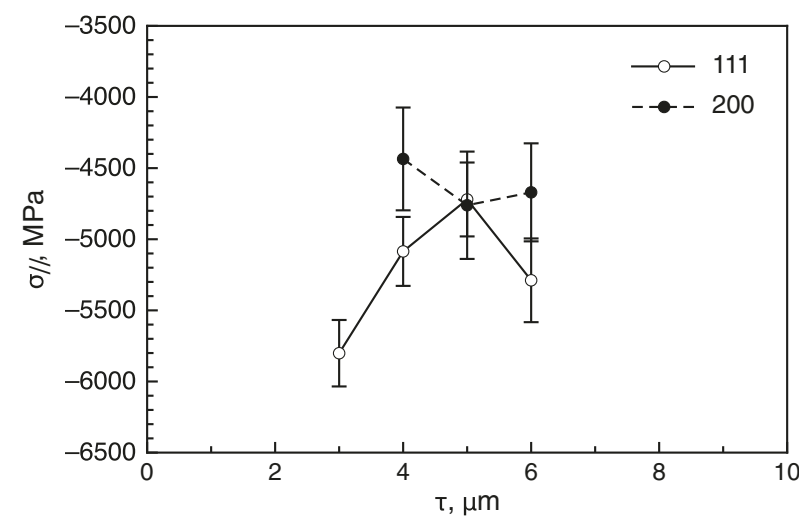

Fig. 6. Residual stress-depth profiles $\sigma_{/ /}$evaluated from 111 to 200 diffraction lines of expanded austenite from the $\sin ^{2} \psi$ plots at chosen information depths, $\tau$, reconstructed from lattice-spacing-depth profiles $\left\langle d_{\psi}^{h k l}\right\rangle$ measured from the scattering vector method applied to a nitrided $316 \mathrm{~L}$ stainless steel.

The actual depth profiles could be obtained by reconstructing the actual lattice spacing profiles from those in Fig. 3a by assuming a polynomial description of the actual profile (for the case of layer/substrate systems see [5]).

\subsection{Composition}

Clearly, the nitrogen content decreases with depth, as anticipated for a growth process largely governed by solid state diffusion of nitrogen through the developed layer. Presuming local equilibrium at the surface in an unconstrained condition, the nitrogen content at the surface would be $y_{N}^{s}=0.61$ [24]. This predicted value compares favourably with the present results, as suggested by extrapolation of the current experimental data towards the surface. Actually, a discrepancy would be expected between experimental and predicted surface concentrations as a consequence of the huge compressive stresses, which affect the thermodynamics of the system, such that the solubility is reduced as compared to the unconstrained condition [27]. In this respect it should also be mentioned that the adopted elastic constants were assumed to be identical to those for austenite. For the nitrogen content close to the unnitrided stainless steel substrate (at a depth of $16 \mu \mathrm{m}$ ) a content corresponding to a ratio $\mathrm{Cr}$ : $\mathrm{N}=1: 1$ (i.e. $y_{N}=0.17$ ) is expected at the transition from expanded austenite to "substrate". It is not possible to make an accurate extrapolation of the few present data to this information depth, but a first estimate provides a value of 0.21 , which is in fair agreement with the predicted value, taking the uncertainty into account.

\subsection{Stacking fault probability}

In this discussion it has to be remarked that the Warren method for the determination of stacking fault probabilities only applies for relatively low stacking fault probabilities and that the method by Velterop et al. [28] should be preferred for probabilities of values determined. Seen in this light the current evaluation should be considered a first attempt. Interpreting stacking faults in terms of the Velterop-model would require additional measurements.

The stacking fault probability increases with depth from a small value for shallow depths to a higher value closer to the "substrate" and is opposite to the depth dependence of strain-free lattice parameter. The origin of plastic deformation in expanded austenite is plastic accommodation of the composition-induced stresses in the growing expanded austenite zone, which exceeds the yield stress. It has been demonstrated convincingly that grain rotation and texture changes occur as a consequence of the plastic accommodation [23,29]. If the stacking faults are caused by this plastic deformation, it would be expected that the stacking fault probability is highest at the surface and decreases with depth. Provided that the evaluation procedure is correct and the assumptions made are justified, the present data show the opposite trend (within the small information depth range where the analysis can be made). This could be understood as follows. The part of the expanded austenite zone that grows into the "substrate" can accommodate the compositionally induced lattice misfit largely elastically. ${ }^{5}$ Ahead of the growing expanded austenite the compensating tensile stress in the unnitrided (and not strengthened) austenite leads to deformation martensite and plastic deformation. Upon continued nitriding this structure is transformed into expanded austenite but it could be that the stacking faults remain. For the part closest to the surface, in an early stage of nitriding, such stresses in the unnitrided austenite can be (partly) relaxed by the adjacent surface and inhomogeneous thickness of the expanded austenite zone.

\subsection{Residual stress}

The stress data for 111 and 200 show a trend of a decreasing residual compressive stress with increasing information depth. In this respect it has to be noted that the stress values at the largest accessible information depths for both 111 and 200 are very sensitive for small variations in the data, because the number of data contributing to the $d_{\psi}$ vs $\sin ^{2} \psi$ graph decreases with increasing $\tau$ (cf. Fig. 3 for 111). These data should therefore be considered as less reliable.

The occurrence of residual stresses of the magnitude observed in Fig. 6 is consistent with the previous work [16], where depth profiles of stress and composition were reconstructed from measurements after (destructive) successive layer removals. The present method has the advantage that significantly shorter measurement times are necessary and no tedious removal of thin (sub)layers from the sample is necessary, which affects the stress state. On the other hand the actual stress profile is not obtained, only a diffracted intensity weighted average.

\section{Conclusion}

The present work explores the use of the scattering vector method for non-destructive X-ray diffraction analysis and separation of composition-, stress- and stacking fault probability gradients in a functionally graded material. Based on the energy-dispersive method, complementary information can be deduced from recording various diffraction lines simultaneously such that from assuming an identical strain-free lattice parameter evaluated from these reflections, the composition and stacking fault probability can be estimated. The results appear to be in agreement with earlier work on a similar system. The advantages of the present method are relatively short measurement time and a non-destructive analysis. The disadvantage is that no actual profiles are obtained, but rather diffraction intensity weighted averages are assigned to the information depth. The latter is maximally half the layer thickness, so the deeper part of the layer remains "invisible".

\section{Acknowledgements}

Financial support from the Danish Research Council for Technology and Production Sciences under grant no. 274-07-0344 is gratefully acknowledged.

\section{References}

[1] P.J. Withers, H.K.D.H. Bhadeshia, Mater. Sci. Technol. 17 (2001) 355.

[2] I..C. Noyan, J.B. Cohen, Residual Stress, Measurement by Diffraction and Interpretation, Springer, New York, 1987.

\footnotetext{
${ }^{5}$ Note that nitrogen in austenite leads to strengthening and, thus, an increase of the yield stress.
} 
[3] V. Hauk, Structural and Residual Stress Analysis by Nondestructive Methods, Elsevier, Amsterdam, 1997

[4] M.A.J. Somers, E.J. Mittemeijer, Metall. Trans. A 21 (1990) 189.

[5] T. Christiansen, M.A.J. Somers, Mater. Sci. Eng., A 424 (2006) 181.

[6] Ch Genzel, Phys. Status Solidi A 146 (1994) 629.

[7] A.J. Allen, M.T. Hutchings, C.G. Windsor, C. Andreani, Adv. Phys. 34 (1985) 445

[8] A. Pyzalla, J. Nondestruct. Eval. 19 (2000) 21.

[9] Ch Genzel, in: E.J. Mittemeijer, P. Scardi (Eds.), Diffraction Analysis of the Microstructure of Materials, Springer Series in Materials Science, 68, 2004, p. 473.

[10] H. Ruppersberg, Adv. X-Ray Anal. 37 (1994) 235.

[11] Ch. Genzel, I.A. Denks, R. Coelho, D. Thomas, R. Mainz, D. Apel, M. Klaus, J. Strain, Analysis 46 (2011) 615.

[12] C. Stock, Ch. Genzel, W. Reimers, Mater. Sci. Forum 404-407 (2002) 13.

[13] M. Klaus, Ch. Genzel, H. Holzschuh, Thin Solid Films 517 (2008) 1172.

[14] Ch. Genzel, C. Stock, W. Reimers, Mater. Sci. Eng., A 372 (2004) 28.

[15] M. Klaus, W. Reimers, Ch. Genzel, Powder Diffr. (Suppl. 24) (2009) S82.

[16] T.L. Christiansen, M.A.J. Somers, Int. J. Mater. Res. 100 (2009) 10.

[17] T.L. Christiansen, M.A.J. Somers, Metall. Mater. Trans. A 40 (2009) 1791.
[18] Ch. Genzel, I.A. Denks, J. Gibmeier, M. Klaus, G. Wagner, Nucl. Instrum. Methods Phys. Res., Sect. A 578 (2007) 23.

[19] Ch. Genzel, S. Krahmer, M. Klaus, I.A. Denks, J. Appl. Crystallogr. 44 (2011) 1.

[20] Ch. Genzel, J. Appl. Crystallogr. 32 (1999) 770.

[21] H.M. Ledbetter, Br. J. Nondestruct. Test. (1981) 286.

[22] T.L. Christiansen, T.S. Hummelshøj, M.A.J. Somers, Surf. Eng. 26 (2010) 242.

[23] J.C. Stinville, P. Villechaise, C. Templier, J.P. Rivière, M. Drouet, Acta Mater. 58 (2010) 2814.

[24] Th. Christiansen, M.A.J. Somers, Metall. Mater. Trans. A 37 (2006) 675

[25] B.E. Warren, X-ray Diffraction, Dover Publications Inc., 1990

26] T. Christiansen Ph.D thesis, Low temperature surface hardening of stainless steel", Technical University of Denmark 2004.

[27] T. Christiansen, K.V. Dahl, M.A.J. Somers, Mater. Sci. Technol. 24 (2008) 159.

[28] L. Velterop, R. Delhez, Th.H. de Keijser, E.J. Mittemeijer, D. Reefman, J. Appl. Crystallogr. 33 (2000) 296.

[29] C. Templier, J.C. Stinville, P. Villechaise, P.O. Renault, G. Abrasonis, J.P. Rivière, A. Martinavičius, M. Drouet, Surf. Coat. Technol. 204 (2010) 2551. 